Chapter 8

\title{
Home Truths: Teaching Canadian Literatures in Spanish Universities
}

\author{
Eva Darias-Beautell
}

Mavis Gallant's award-winning collection of short stories Home Truths dispenses neither truth nor a home for the reader, who is rather drawn "into the tricky labyrinth of human behaviour" (McClelland.com, 2010) only to be left "feeling adrift, the world slightly askance" (Allardice, 2009). Depicting a wide spectrum of Canadian characters in the most diverse situations and often travelling within Canada or abroad, the collection epitomizes Gallant's ironic take on the question of Canadianness, which starts with the inscription of a profound sense of homelessness produced as much by historical circumstances as by her characters' own sense of dislocation. Herself a paradigm of the expatriate Canadian, Gallant is both outside and inside her intricate worlds of fiction where belonging is staged in terms of a shifting sense of groundlessness, and where words "are heard but not understood" (Howells, 1987). In the story titled "The Ice Wagon Going Down the Street," the protagonists sit around the breakfast table at their sister's apartment in Toronto disguised in their "peacock" gowns as they reminisce about a (failed) past in the international scene. The question of Canadian identity is implicitly discussed in this context, weighed somehow uncomfortably between an ice wagon (going down the street), an image of a disappearing rural family life in the Saskatchewan winter, and the Balenciaga that Sheila possesses, an increasingly soiled black dress, once a symbol of social status and cosmopolitan glamour. And, on this rather disconcerting note, the story ends by imparting a permanent sense of indecisiveness and loss.

A similar sense of indecisiveness seems to have pervaded Canadian Literature as a field of study and research since its inception and is still resonating in our pedagogical practices outside Canada. In the 2004 didactic guide for the Canadian Literature course taught at the UNED (Universidad Nacional de Educación a Distancia), for instance, Teresa Gibert (2004) writes: "Since all national literatures are understood as reflections of national experiences, it comes as no surprise that Canadians have often tried to define their literature as the embodiment of the distinctive character of the nation. But there is no easy definition for Canadian literature because there is no unanimous agreement as to what Canadianness is, except for considering it an extremely problematic category." Bespeaking the complexities of Canadian Literature as a field, Gibert's words disclose the labyrinthine structures of our object of analysis, for no other national literature exists on the basis of its own permanent questioning. 
Furthermore, her words betray the tautological nature of the institutional practices and conditions both inside and outside Canada that frame our study, teaching, and promotion of CanLit in the international arena.

This essay will provide a critical overview of the teaching of Canadian literature in Spanish universities in the past sixteen years, from the 1994 curricular reform, in which most current courses on Canadian literature found their place, to the present introduction of new curricular designs in 2010 as part of the Bologna Process. ${ }^{174}$ This temporal framework is not only complicated in a large reform affecting studies at all European universities and involving a significant epistemological shift but also in a revision of the critical pedagogies we use in the classroom. In the North American literary context, this period also coincides, on the one hand, with renewed debates about the canon and canonical processes such as the often extra-literary principles of inclusion or exclusion which conform to what we call the literary tradition, and with the end of identity politics and the beginning of new forms of social and literary paradigms, on the other (Miki, 2008). ${ }^{175}$

My analysis will assess the impact of those changes in Spanish universities by focusing on three main interrelated issues. In the first place, I will deal with the teaching of Canadian literature from an institutional perspective, including an analysis of the obstacles found process of introducing of the new subject over the past sixteen years, as well as the difficulties encountered by attempts at circumscribing Canadian literature as independent from "Other/Commonwealth/ Postcolonial Literatures," on the one hand, and "American Literature," on the

174 The information I provide in this essay is based on data initially collected for a presentation at the "Postcolonialism and Pedagogy Symposium: Canadian Literatures in the Classroom" (University of Ottawa, 3-5 May 2002), which was then reassessed and updated for a round table organized by the editor of this volume, at the International AEDEAN (Spanish Association of Anglo American Studies) Conference held at the University of Huelva in December, 2006. For the present work, I have revised and updated the data again by consulting every university web page as well as by establishing personal contact with other Spanish colleagues. I wish to thank Pilar Somacarrera, María Jesús Hernáez, Belén Martín, Ana Fraile, and Begoña Simal for their help and the information provided. My special thanks go to Teresa Gibert at the UNED for sending me the Didactic Guide of her course.

$\mathbf{1 7 5}$ It should be noted that the information presented refers exclusively to the teaching of Canadian literature in English. The specificity of Canadian literature as a bilingual field and its uneven share in the different literature departments are unfortunately beyond the scope of this essay, and outside the thematic of this book. An analysis of the situation of Canadian literature in French, however, would probably reveal how the strict separation between departments has produced large institutional obstacles to the development of the field. Any type of collaboration between the two areas often implies the always complex institutional collaboration between different departments as well as interdisciplinary work in two languages and two cultures. The result in Spain, as well as in many other countries, has been the almost complete separation of the two fields. 
other. Secondly, I will examine the contents of the programs, their inclusions and exclusions, the choice of terminology such as "mainstream" and "minority" writers, and the view of the Canadian national identity and tradition they implicitly construct. Here I will look at the influence on the academic syllabi in Spain of the parallel canon debates taking place in Canadian universities. The role, influence and accessibility of literary histories, anthologies and texts will also assessed in the light of this connection. Thirdly, I will discuss the teaching methodologies and the theoretical approaches used, including a critical appreciation of the use of traditional methods of close reading and thematic analysis as well as the state of postmodern, feminist and postcolonial interpretations of Canadian literatures. In this case, I will look at the relationship between the syllabi and the critical pedagogies used in the classroom.

\section{Enter: Canadian Literature}

As in most European universities, the introduction of Canadian literature in Spanish institutions largely took place in the early 1990s as part of the opening up of the programs to the literature of other countries. That is, it was born at the peak of postcolonial theory and was therefore intimately linked to the introduction of Commonwealth or Other Literatures in English as a field in its own right. The latter was a result of what Bernard Bergonzi (1990) called "the explosion of English," a move that created the possibility of articulating for the first time three different areas of analysis and research within the study of literature in English: English, American (US) and Commonwealth Literature. Only a few decades earlier, American literature had undergone a similar process of identification in order to establish the disciplinary independence that we now take for granted. The explosion of English followed, and, being the direct result of the decolonizing histories of the second half of the 20th century, was perceived as one more step in the creation of separate areas of enquiry within the field of literary studies in English that matched that process of decolonization.

Soon, however, the very categories on which it was constructed proved inexact, insufficient or unsatisfactory for many reasons. Today, for example, the adjectives "English" to refer to Wales, Scotland and Ireland, or "American" to mean literature from the U.S.A., although still widely used, have been repeatedly questioned by critics and writers alike. But perhaps the most problematic of all is the category of "Commonwealth," including countries as different from one another as India, South Africa or Canada. It is undeniable that Canada has many elements in common with other British ex-colonies around the world, and very specifically with settler colonies such as Australia, with which, as critics have argued, Canada shares a twisted history of complicity with colonial discourses and powers, as well as their (mild) critique (Brydon, 1995; Lawson, 1995). 
The notion of postcolonialism, in this context, whether it is interpreted as a chronological or an epistemological category, has always been problematic in the Canadian case, and very much so when applied to the literary production of white Canada (Mukherjee, 1990; Hutcheon, 1991). That these questions do not seem to have had much impact upon the curricular structure and the devising of Canadian Literature courses worldwide, most of which have been created and are still taught under postcolonial or commonwealth rubrics, attests to the limitations of literary discourses and reflects as much the institutional contexts as the academic pressures in which the field has been born. ${ }^{176}$

Strategically effective in the moment of its creation, the Commonwealth umbrella has paradoxically been an obstacle in the full articulation and independent development of the field of Canadian Literature. As I will show, the courses that have studied Canada within its North American location are an exception and have taken place at the cost of ignoring its actual geographic, cultural, social, and political contexts. The question of whether Canadians have, for better or worse, always seen themselves as North Americans, and therefore, closer to the United States than to other countries of the old British Empire has not figured prominently in the institutional agendas. The obvious historical and cultural differences between the two neighbouring countries have been, in turn, exposed and explicitly brought to the foreground of official and academic discourse both within and outside Canada. Furthermore, embodying a complex neo-colonial threat, the powerful proximity of the United States of America has fed nationalist discourses in Canada since its inception, and, in fact, a significant part of the process of construction of a Canadian identity has taken the form of opposition to the southern neighbour. On the one hand, such processes prove symptomatic of the large basis of comparison between the two countries, since, as the poststructuralists have taught us, all opposition is identification and vice versa. On the other, Canadians' own reluctance to be included in a comparative North American literary tradition (and the scarcity of works in this line attests to it) is understandable, given the continuous practice of appropriation and absorption of foreign production by American critics. As Smaro Kamboureli (2012) writes in a rather different context: "When Canadian authors like Margaret Atwood or Joy Kogawa do "make it" south of the Canadian border, it is usually because they have their Canadianness suspended or strategically co-opted; a lot of critical work on Obasan produced by Asian American scholars barely nods to its Asian Canadian origins."

$\mathbf{1 7 6}$ In this regard, the academic position of the specialized professor within the hierarchical structure of his or her institution is and has been a decisive factor in the introduction of Canadian Literature courses in the Spanish syllabi. 
The Spanish situation is not foreign to these discussions and, as in most European universities, the initial challenge was (and still, to some extent, is) the circumscription of the field "Canadian Literature" around the mentioned parameters within the various English Studies programmes. Back in the early 1990s, the courses labelled "American" or even "North American" were exclusively dedicated to the study of the USA, and there was not one single program in Spain that included Canadian content in their "(North) American" literature courses. The general tendency, therefore, was towards the insertion of Canadian literature first as part of the programs of Commonwealth studies and gradually as monographic (usually optional) courses within English Studies. This was the case of at least eighteen English Studies programmes (around $44 \%$ of all programmes in Spain) by the late 1990s. Yet, once the opening of the literature programs took place albeit in this generalist fashion, it proved extremely difficult to set Canadian literature courses as an independent field: that is, as a distinctive field of knowledge, enquiry and research intersecting with but also differing in relevant modes from other national literatures. At that moment, only three universities in Spain advertised undergraduate courses with the name of "Canadian Literature" (Barcelona, Lleida and UNED). Most often, the case was that, given the existence of two optional courses with names such as "Other/New Literatures in English", "Commonwealth Literatures" or "Postcolonial Literatures" I and II, one of these options was frequently entirely dedicated to the literature of Canada (a choice sometimes marked with a course subtitle). The other, less visible, mode of entering the programs was to include one full topic on Canadian literature within a larger literature course with any of the above names. Finally, perhaps inaugurating a move of the field towards cultural studies that has today been confirmed, there was always the possibility of introducing Canadian-content materials in historically-oriented courses such as "History and Culture of the English-Speaking Countries," present in all English Studies programs in Spain.

Initially, these data, although not thoroughly impressive, seemed to constitute an undeniable proof of the ever stronger presence and the steady development of the field of Canadian Studies in Spain. It was clearly a reflection of a large institutional initiative launched by the Canadian Government through its Department of Foreign Affairs and which, in Spain, led to the founding of the Spanish Association for Canadian Studies in 1988. The opening of three University Centres for the Study of Canada (Barcelona, Extremadura and La Laguna) followed suit with the intention of providing both the physical space and the academic forum to promote the research and teaching of Canada in Spain. Soon, however, these goals that had materialized in the late 1990s proved to have reached a dead end, as the growing uncertainty about the future and the present stagnation of some of the above initiatives are making sadly evident. 
Many factors could be mentioned in relation to this process of involution, the most relevant here perhaps being the shift in Ottawa's strategies of selfpromotion towards different priority areas and the consequent cuts in funding programs, on the one hand; and the implementation of the Bologna curricular reform in all Spanish universities, on the other, fusing back some of the fields that had been slowly taking off, and proposing instead general and more comprehensive degree programs in the humanities. As a result, some courses have disappeared from the curricula or their growing specificity has faded. With the incorporation of two new "Canadian Literature" courses in their respective English Studies degrees, the Universities of Salamanca and La Laguna constitute exceptions to this tendency. Also figuring as an exceptional case, the UNED (Universidad Nacional de Educación a Distancia) continues to offer a very specific and rather ambitious course on Canadian Literature in English whose contents I will briefly discuss below. Canadian literature content still figures prominently, although within more general umbrella courses, in the English Studies programs at the universities of Vigo, Oviedo, UAM (Universidad Autónoma de Madrid) and Huelva. A timid move forward, somehow compensating for the vanishing of some courses at the BA level, seems to show in the inclusion of Canadian content subjects in the new MA Degrees (La Rioja, Vigo, Oviedo and Salamanca), and most significantly in the creation at the University of La Laguna of an MA in North American Studies exceptionally offering an interdisciplinary study of the three countries of the NAFTA and including the possibility of a major Canadiancontent itinerary. Strategically placed between the students' first degree and the PhD programmes, these initiatives at the Master's level, although still very incipient, may introduce a second moment in the teaching of Canadian literature in Spain, building new paths of approach to and engagement with the subject and devising attractive bridges towards continuing research in the field.

\section{Canon Disorders}

Rather than being driven by the desire to study a formerly non-existent corpus of national literature, the very impulse to insert the study of "new" literatures in the "old" programs involved and mirrored a larger shift in the notions of aesthetic value as well as in our own responses and approaches to literary discourses. Few critics would disagree today with the assertion that the last decades of the 20th century witnessed a significant transformation of Western culture, bringing a radical change that affected our notion of literature, and therefore, of the canon. Postmodern thought and its related theoretical movements, such as poststructuralism and post-colonialism, had a tremendous impact on the humanities, on the ways we had conceived the world and its various representations. Within that general reorientation of epistemology, the interest in Canadian Literatures 
was just one more instance of the sudden centrality of what had been historically marginal(ized). At the same time, a focus on the relationship between canon and power became paradigmatic of these larger changes since it opened the field to an ever-expanding interdisciplinarity, based, in turn, on our awareness of the constructedness of the subject through multiple and interacting constituencies such as class, race, gender, and so forth. ${ }^{177}$ In only twenty-five years, from the cultural nationalism of the 1960s to the Act of Multiculturalism in 1988, Canada lived this process twice, as it were: as an undeniable part of postcolonial histories, it experienced a new national prominence vis-à-vis colonial powers; as complicit with those powers and subject to the complex multiethnic character of its culture, it experienced a redefinition of the recently-constructed national identity and the restructuring of its literary tradition that came with it, a key reformation process that critics Coral Ann Howells and Eva-Marie Kröller (2009) have referred to as "switching the plot" of Canadian literary history. The intricacies of these huge and relatively fast transformations have definitely framed literary production in Canada as well as the ways we teach it in Canada and outside. As Smaro Kamboureli (2012) convincingly argues:

While as critics we do not always focus on canonical texts [...]the critical enterprise is invariably marked by a disposition to identify value and systemize knowledge, as well as by the "tendency to modernize the syllabus" and critical discourses, sometimes "at the expense of older works" (Guillory 15). The latter point speaks directly to the emphasis placed in the last decades of the past century upon the literary productions by First Nations authors and authors called ethnic, diasporic, migrant, or postcolonial that has radically questioned the Western ideologies that have long shaped canonization. This troping toward otherness - the mark of minoritization these literatures have in common - involves a direct engagement with racialization and cultural diversity but also with the historical and systemic inequities inscribed upon minoritized cultural communities through the ways in which the hegemonic nation-state manages diversity as yet another phase of its modernity. [....] Indeed, the expansion of critical studies toward this direction has predominated academic production and curricular and pedagogical changes in this time, and there is no shortage of studies discussing the pros and cons of such developments.

I will return to the issues of otherness, minoritization and multiculturalism raised by Kamboureli in the above quote. But, first, I would like to comment

177 The collection Canon Disorders (Eva Darias-Beautell and María Jesús Hernáez, eds.) provides a discussion of these issues in the context of both contemporary Canadian and American cultures, including analyses of disordering texts and films. 
on three interesting developments or effects that the institutionalization of "new" literatures in Spain have produced, even if only as by-products, and that have modified our vision of the canon and of literary studies in general. The first one is related to the attraction of the contemporary. A notion of the canon, as defined by T.S. Eliot as a corpus of works that must have passed the proof of time and traditionally, therefore, excluding contemporary production, had been tacitly practised in English departments, where much time, devotion and attention were often given to Medieval, Renaissance, Restoration, Romantic or (increasingly) Modernist Literatures to the obvious detriment of the second half of the 20th century. The teaching of Canadian literature, as well as of other national literatures defined as "new," has overthrown those conditions, seen now rather as partly elitist and prejudiced. Moreover, the fact that Canadian literature is contemporary, most syllabi dealing with 20th-century texts, is increasingly being perceived as an advantage and probably resides at the basis of its success, at least in Spain, in eliciting cultural and contextual references which are closer to the students' own.

The second development I wish to briefly mention deals with the power of the market and the related extra-literary institutional practices. In the first phase of the 1990s, a good part of our syllabi were designed, sometimes even inadvertently, according to the availability of texts in Spain, and this coincided in many cases with what Robert Lecker has called "the New Canadian Library tradition." As Lecker explains in his then controversial book Making It Real (1995), the configuration of the Canadian canon in the 1960 s and the 1970 s had largely been the work of the influential Canadian publisher McClelland and Stewart, whose choice, in its turn, had had much to do with the availability of texts at that time as well as with the existence and amount of book royalties. Even though the situation today has notably changed and the access to sources as well as the distribution of Canadian books have spectacularly improved with the Internet, we could arguably contend that it still is those texts that can be usually found in the Canadian literature syllabi in Canada and abroad, at least in panoramic or survey courses: Frances Brooke, Sinclair Ross, Hugh MacLennan, Robertson Davies, Leonard Cohen, Margaret Laurence, Mavis Gallant, Alice Munro, Margaret Atwood in fiction; D. G. Roberts, D. C. Scott, E. J. Pratt, Dorothy Livesay and Al Purdy in poetry.

A further development in this context talks about the institutional prevalence of the narrative genre. Implicitly supported by the contemporary emphasis on the narrative nature of all forms of knowledge, the literary production of the country in the 1990 s seemed to be also mostly narrative production and most seminal critical works were dedicated to the genre (see, for instance, Hutcheon 1988; Bayard, 1989; Davey, 1993; Turner, 1995). This circumstance may well be another extended effect of the operations of the book market: fiction being the most consumable of all literary forms as well as often the most complicit 
with capitalist ideologies. Yet the fact today is that the most acclaimed Canadian writers, both at home and internationally, are great narrative writers and most syllabi reflect this choice by giving a declared preference to the study of novels and short fiction.

Regarding the course contents, survey courses, originally designed to provide the student with a panoramic view of the literature, were common in our universities in the early and mid-1990s, usually containing an historical introduction, followed by a selection of mainstream texts and writers arranged chronologically (often a combination of any of the NCL writers mentioned above) and, increasingly, as the decade moved on, ending with one or two topics dedicated to multiculturalism. Today, however, there are only two programmes in Spain which offer such a choice (Salamanca and UNED) and both prove symptomatic of what Daniel Coleman has called "white civility," or the "static and reified idea of civility, which has its foundations in White, British gentlemanliness" (Coleman, 2007). In Canada, Coleman (2007) argues, "the sharp edges and striations of civility have been most consistently and explicitly drawn along the borders of race and ethnicity." The Canadian Literature syllabus at the UNED seems paradigmatic of this choice, offering an overview of the field from the mid-19th century to the early 1990s in fiction and poetry, author rather than text based, and including such canonical writers as Moodie, MacLennan, Purdy, Laurence, Munro, Atwood. Out of twelve topics in total, the three final topics are dedicated to Native Canadian Literature (Highway and King), Ondaatje (with a topic of his own), and "Multicultural Fictions" (Kogawa and Mistry), respectively.

Most often, however, partly due to spatial and temporal limitations, partly a reflection of the contemporary debates about the validity of the teleological and comprehensive project the panoramic course implies, syllabi have opted for monographic courses of a different kind. By the late 1990s, materials taught usually included writers such as, in order of their frequency, Atwood, Laurence, Ondaatje, Kroetsch, Gallant, and Munro together with Highway, King and Jeannette Armstrong in the "Native category," and Kogawa, Nourbese Philip and Mistry in the "ethnic category." In the present decade, fully incorporating minoritized writers, courses have definitely shifted away from the panoramic objective and into the analysis of selected texts around specific topics: identity, region, gender, genre, history, race, landscape, and so forth.

This tendency was in fact a reflection of similar discussions happening in Canada over the official policies of Multiculturalism. Focusing on the connections between multiculturalism and writing produced a literary restructuring that was, in turn, echoed by the government policies both within and outside the country. Despite their many pitfalls, multicultural policies were perceived as giving an unprecedented impulse to the writing and publishing of texts by authors of all different cultural backgrounds. Yet it gradually became evident that these transformations, perhaps despite their original intention 
to transcend certain categories, had been designed on the very binary logics they wanted to subvert, namely on the opposition between mainstream and minority literature. Anthologies like Linda Hutcheon's and Marion Richmond's Other Solitudes (1990) and Smaro Kamboureli's Making a Difference (1995), both of which have been extremely influential and helpful for pedagogical purposes outside Canada, unwittingly contributed to the perpetuation of these binaries by implicitly articulating a full body of "multicultural" literature outside "normative" Canadian literature. At the time, this came as a salutary strategy to counterpoint the conservative and still powerful literary discourse embodied by Russell Brown and Donna Bennett's An Anthology of Canadian Literature in English (1983), also widely used in university courses in Canada and Europe. However, as the second edition of Kamboureli's Making a Difference (2006) and the third edition of Brown and Bennett's Anthology (2010) attest to, the original parameters and institutional, social, cultural and literary conditions that produced the multicultural aesthetics have changed in the past fifteen years and the division between mainstream and minoritized writers on which it functioned has been largely questioned on all fronts. ${ }^{178}$

Issues of appropriation, racialization, essentialization, and representation have now been at the forefront of academic discourses for long enough to have determined our selection of corpus, our pedagogical choices and our methodologies. We are no longer comfortable in the arena of identity politics, defined by Ashok Mathur (2007) as "at once liberating and constraining, full of potential and contradiction, presenting to us opportunities (at times somewhat mercurial ones) to disturb a social fabric that had become complacent in its homogeneity and lack of attention to power relationships." The end of identity politics has definitely set in motion a rescaling of subjectivity along the transnational parameters of what Roy Miki has called the "global drift," affecting our definition of both the national and the literary and thereby shaping our pedagogical practices. But the death of the multicultural moment in Canada has also happened with an ironic twist: the mainstreaming of many writers of colour. "What began as a brown wafer begging to be tasted" asserts Mathur (2007), "has

178 My use of the term "minoritized" is intended to mark that turning point. Kamboureli responds to these changes by including a new selection of relatively unknown writers beside whom some of the most famous multicultural writers become canonized. Brown and Bennett, well aware of the market exigencies and the pedagogical institutions to which the anthology may appeal, make a move towards increasing diversity: "The new edition is more inclusive, with more women and aboriginal writers and more writers from different ethnic backgrounds. In putting the anthology together, the editors paid close attention to the kinds of themes people are currently teaching, such as questions of identity, contact across cultures, fragmentation, and mobility" (Oxford University Press website, An Anthology of Canadian Literature in English, third edition). 
become the body it once opposed." A discussion of the ambivalent mechanisms of how previously minoritized writers have become CanLit is well beyond the scope of this paper. Yet, since this transformation is increasingly showing in our teaching practices and syllabi, I believe that we should be alert to the contradictory implications that these changes may involve: by mainstreaming, reading, writing about and teaching previously ignored or marginalized texts, we run the risk of practising the same lack of attention to power politics that we initially criticised, often overlooking the market desire for a particular focus as well as tacit institutional interests in fostering such directions. ${ }^{179}$ Therefore, what we are teaching and how we are teaching it is thus a clear reflection not only of our specific institutional contexts in Spain but also of these literary debates and cultural transformations happening in Canada.

\section{Teaching Methodologies}

How are we approaching Canadian literature in the Spanish classroom? In contrast with the pedagogical situation in Canada, Canadian Literature in Spain barely exists outside the university institution, being constantly produced by/in those institutional frameworks as well as by/in the epistemic structures in which it is studied and taught. Additionally, given the fact that our courses are often the students' first contact with the subject - a general introduction being usually mandatory that provides them with the required social, historical and cultural background - the field is specially vulnerable to changing ideologies, personal criteria and the arbitrariness of the processes of knowledge production.

A glance at those introductions reveals the kinds of explicit and implicit methodologies that underlie the particular courses. The most common critical practice seems to also be the oldest: the close reading of texts. This methodology, conventional by definition, has not necessarily been conservative in the Spanish case since it has often opened the Canadian text up to a wide range of interpretations, as well as to the frequent incorporation of contemporary theoretical discourses that have gradually, albeit sometimes slowly, made their way into the classroom in this reversed fashion (from the text to the theory). In fact, along with the common practice of close reading (not always theoretical in its methodology), the theoretical and critical frameworks used in the past 20 years have invariably moved in the postmodern, postcolonial and/or feminist arenas,

179 See Mathur (2007). A further analysis of this development in the context of the reception of Asian Canadian literature in Spain is found in Belén Martín-Lucas's contribution to this volume. 
often consisting of a combination of these. Elsewhere, I have found interesting connections between the type of syllabi and the critical framework used. Thematic readings of literature, although in extinction, continue to be practised, especially in the context of survey courses, where an author-based analysis is still also frequent (or even coming back from the tomb where Roland Barthes had put it ${ }^{180}$ ). The issue of Canadian identity, for very many years the Canadian topic par excellence, is definitely vanishing from our courses, as it is, I think, from Canadian literature itself, gradually leaving its place to other foci, national(ist) or otherwise. However, the identity approach had already reinvented itself in the early 1990s, proving very fruitful in combination with postmodern, postcolonial and feminist critical discourses, which in Spain had by then become the most widely used approaches to the literature of Canada. Undoubtedly, this was the result of very influential theoretical works such as Linda Hutcheon's The Canadian Postmodern (1988), a text that wittily argued for the intrinsic postmodernity of the Canadian nation as well as for the necessary interconnection among postmodern, postcolonial and feminist discourses. (In the mid-1990s, 90\% of the courses taught in Spanish universities included Hutcheon's text on their list of basic critical readings.) Increasingly, these methodologies are changing, as are the very syllabi, and becoming more diversified and flexible.

I wish to look briefly at two of those discourses in that they seem endowed with certain specificity when it comes to the teaching and the study of Canadian texts: the feminist and the postcolonial. To discuss Canada's connection with feminist discourses is, in the first place, to locate the country in its North American context, where over the past forty years feminist scholarship has brought to the foreground the complex relationship between canon and power, uncovering the patriarchal ideology of our literary and cultural traditions and pushing the parallel questioning of the Cartesian subject in directions never explored before. Extending to the gender arena the poststructuralist approach to reality, culture, and identity as always already constructed in and by language, North American feminists have consistently challenged our grounds of thought, unveiling canon formation as an ideological operation and arguing thus for its revision. Additionally, Canada is one of the few countries in the world where women writers probably outnumber male writers and the number of prominent women critics and theoreticians is also unusually high. I am particularly thinking of critics Linda Hutcheon, Barbara Godard or Smaro Kamboureli, among many others whose seminal studies of the field have shaped the course and the teaching of Canadian Literature in and outside Canada.

180 Barthes' notion of "the death of the author" was suggested in his book Criticism and Truth. 
Coinciding with the peak of feminist criticism and the success feminist pedagogies in the 1980s, the prominence of Canadian women writers brought about a number of studies that posited the "feminine" nature of Canadian culture itself. Coral Ann Howells's Private and Fictional Words (1987), a book on fiction by Canadian women, begins, as Howells herself writes in the introduction, as an attempt to explore such "parallels between the historical situation of women and of Canada as a nation." At the time, the circumstance that there was no clear definition of the national culture and identity favoured the articulation of symbolic parallels between gender and the nation, and feminist discourses often happened alongside the debates on the nature of Canada as nation, Canadian histories and cultures. The alliance proved appealing and fruitful: Margaret Atwood explores the connection between gender and (Canadian) nationality in much of her fiction of that period: Surfacing (1972), Lady Oracle (1976), Cat's Eye (1988); Susan Swan's character Anna Swan, in The Biggest Modern Woman of the World (1983), writes: "Indeed, to be from the Canadas is to feel as women feel - cut off from the base of power;" (Swan, 1083) and Mavis Gallant's character Linnet Muir, in Home Truths (1981), could be read as an allegory of the nation. In 1994 Patricia Smart provided an illuminating analysis of the connections between feminism and nationalism in Canada, arguing that the category "nation" had been systematically excluded from critical studies on Canadian women's writings. Yet, she continues, "it has been their work, perhaps more than any other in the last decade, that has given me the sense that I belong to a national community." Even though the approach has gradually faded and the effectiveness (and advisability) of such parallels between nation and gender have now been largely questioned, the fact is that the strategy has had its impact on the ways we teach Canadian literature, determining not only the choice of primary work in the syllabi (were women writers are almost always the majority), but also the critical apparatus used in the course. Most recently, feminist approaches have developed in interesting combinations with postcolonial ones, as shown in the programs at the University of Vigo, for instance, including texts by Dionne Brand, Sherazad Jamal, Rita Wong, Suzette Mayr and Nalo Hopkinson, as well as in publications such as Her Na-rra-tion: Women's Narratives of the Canadian Nation (2008), papers collected from the Conference with the same name held at the University of Nantes in 2007.

Postcolonialism is precisely the other very powerful theoretical discourse in and about Canada that I wish to discuss in its specificity. As I have mentioned above, the use of postcolonial theories and concepts to analyse the Canadian production at large has never been fully accepted and is still today a matter of dissent. The almost complete absence of references to the postcolonial circumstances of the country in Canadian literary histories and university courses up to the 1980 s reveals the extent to which Canadians have been 
reluctant to acknowledge both their colonial past and their neo/postcolonial present. ${ }^{181}$ The situation in Spain initially mirrored this reluctance, and, although by the late 1990s this was changing fast, the full articulation of the (ambiguous) historical and cultural position of the "settler" subject has never really found a sound place in most syllabi. ${ }^{182}$

The 1990s witnessed interesting and sometimes heated debates over the validity of postcolonial theory to study Canadian texts, which were closely followed by Spanish and other European scholars. For critics like Arun Mukherjee (1990), it is the category of race that draws a sharp line between postcolonialism, a cultural paradigm in which the writing of nonwhite Canadians must be placed, and postmodernism/post-structuralism, a group of practices that should be best circumscribed to the writings of white Canadians. In a similar vein, Linda Hutcheon's "Circling the Downspout of Empire" objects to the use of the term "postcolonial" in the case of "white" Canada, which she sees as somehow "exaggerated" (Hutcheon, 1991). Although acknowledging the weight of a historical dependence on the British Empire and the effects of an imminent cultural and economic American neocolonialism, the term "postcolonial," Hutcheon (1991) argues, would be most appropriate to describe Native Canadian literary production whose common use of counter-discursive strategies would offer fruitful grounds for postcolonial enquiry. The notion of the "settler" colony probably meant one of the most important developments in this context and came to clarify some aspects of these discussions. It became obvious that postcolonial theory, as Diana Brydon (1995) notes, "can only illuminate Canadian histories and contradictory complicities if its range is extended beyond what the West finds exotic and entrancingly other." Located right at the intersection between at least two centres of authority/authenticity (Europe and Native North America), the settler subject, Allan Lawson (1995) argues, both desires and wishes to erase those historical and cultural referents.

All these critical texts were widely read and discussed in European contexts, gradually making their way into our programs. Lawson's work became key in this regard, since the more we advanced in the analysis of notions and concepts, the clearer the fact became that there were different postcolonial circumstances. His articulation of the postcolonial as a discursive operation rather than as a specific moment in history created new postcolonial epistèmes, not necessarily

181 Brydon (1995) offers a good summary of the history of postcolonial criticism in Canada up to the 1990s. Brydon's article is part of an exceptional special number of Essays on Canadian Writing dedicated to the issue of postcolonialism in Canada.

182 The exception to the rule is Pilar Somacarrera's course, which explicitly approaches Canadian Literature from a postcolonial point of view. 
defined chronologically; and this, in turn, made possible alternatives modes of dealing with the situation of the settler/invader colonies. A discursive notion of the postcolonial also opened the possibility of analysing synchronic as well as intra-national sites of (post)colonial relations. New work in the field, both in Canada and Spain, is being done in these multiple directions, the turning point perhaps being marked by the "Postcolonialism and Pedagogy Symposium: Canadian Literatures in the Classroom," held at the University of Ottawa in May 2002, whose insightful papers, later collected in two volumes edited by Cynthia Sugars, Home-Work and Unhomely States (2004a), are now widely used as critical background material.

New pedagogies are slowly being integrated that stem from those transformations: diaspora, hemispheric, gender and queer approaches, just to mention a few. Ecocritical studies, for instance, stemming from definitions of the national identity in the past three decades in connection with Canada's real and/or imaginary wilderness, but also somehow departing from them, are gradually making their way into the syllabi. Following a period of dismantlement of the above associations, a period characterized by the rise of a fundamentally urban multiculturalism in Canadian literature, a focus on the various representations of nature, seen as construct or as essential and material, seems to be recovering some relevance (Darias-Beautell, 2008). Located at the intersection between texts and critical discourses about them, the new courses intend to address this issue by dealing with questions such as: is there anything Canadian about ecocriticism? What could Canadian writers and critics contribute to it? These pedagogies are symptomatic of a growing tendency of our literature courses and discourses towards cultural studies and, in so doing, towards interdisciplinary analyses. Laura Moss and Cynthia Sugars's recently released two-volume anthology Canadian Literature in English seems paradigmatic of that movement of CanLit towards the cultural and interdisciplinary, as is the collection of insightful and innovative critical essays Trans.Can.Lit, edited by Smaro Kamboureli and Roy Miki, both of which texts are being increasingly used in the Spanish classroom.

\section{Home Truths}

What is the future of Canadian Literature in Spain? And what function, as teachers and critics of CanLit, can we have in its development or its involution? As I have suggested above, in contrast to the social, cultural and political spheres where the field exists as such in Canada, the nature of Canadian Literature in Spain has so far mainly been institutional and confined to the space of the universities. This fact, however, is slowly changing and there is evidence to believe that Canadian 
literature is significantly growing outside the universities. ${ }^{183}$ In any case, the development of the field to the present has been largely the result of the work of individual teachers. These instructors, often the recipients of Government of Canada Awards who have to operate in the midst of institutional and personal resistance towards innovative practices, are within but also somehow exceed the boundaries of those academic institutions where they work, since their reading and writing are also conducted outside their universities in other research institutions and public or personal spaces in Spain, Canada and other countries.

As I have tried to show, our practices are not only affected by the institutional frameworks in Spain and Europe, where the tendency of the current curricular reform in post-secondary education is towards general, comprehensive programs to the detriment of the optional, the minoritarian and the specific. Our pedagogical practices also mirror and are at the same time affected by similar discussions in the Canadian academe, where the survival of the field today is equally a subject of concern. As Smaro Kamboureli asserts (her quote summarizes, somehow, the issues I have discussed in this essay):

The specific trajectories of CanLit bespeak a continuing anxiety over intent and purpose, its ends always threatening to dissolve. This accounts for its intense preoccupation with its formation: its topocentrism; its uneasy relationships with the British, the Commonwealth, and the Americans; its uneven responses to the (post)colonial and its so-called minority literatures; its desire to accommodate global cultural contexts; its obsessiveness with identity; and its institutionalization and celebration through cultural, social, and trade policies. These diverse preoccupations attest to CanLit's specificity, but also to its nervous state (Kamboureli, 2006).

The ongoing problematization of the national as a valid category of enquiry adds up to this state of continuing anxiety. That the "crisis" of the national does not seem to be affecting our courses in English or American literature reveals the extent to which a firm institutional support is more than ever needed both in Spain and in Canada. Yet, in the last instance, I believe that the personal effort of individual teachers to devise, defend, maintain, strengthen and update our courses will continue to be the most powerful driving force.

183 The chapters by Nieves Pascual, Pilar Somacarrera, Isabel Alonso and Marta OrtegaSáez in this collection show the extent and the impact of these changes. 